\title{
Effect of tanniniferous browse meal on nematode faecal egg counts and internal parasite burdens in sheep and goats
}

\author{
R.A. Max $^{1,2 \#}$, A.E. Kimambo ${ }^{2}$, A.A. Kassuku ${ }^{2}$, L.A. Mtenga ${ }^{2}$ and P.J. Buttery ${ }^{1}$ \\ ${ }^{1}$ University of Nottingham, Sutton Bonington Campus, Loughborough, Leicestershire, LE12 5RD, United Kingdom \\ ${ }^{2}$ Sokoine University of Agriculture, P.O. Box 3017, Morogoro, Tanzania
}

\begin{abstract}
The effect of tanniniferous browse meal on faecal egg counts (FEC) and intestinal worm burdens was investigated in sheep and goats infested experimentally with gastrointestinal nematodes. Initially, leaves of different browse tree species were assayed for condensed tannin (CT) content using a colorimetric method to determine concentration and seasonal variations. The level of CT in the leaves ranged between $58-283 \mathrm{~g} / \mathrm{kg}$ dry matter. Seasonal changes in CT levels were influenced by stage of leaf maturity with peak levels after the wet season in June. Leaves of Acacia polyacantha had the highest tannin concentration and were used to test their anthelmintic effect in goats and sheep infested with the nematodes in two separate feeding trials. In Trial 1 an acacia leaf meal supplement (AMS) was offered at $100-130 \mathrm{~g} /$ animal/day for 20 days to growing Small East African goats to investigate its effect on FEC and worm burden. Mean FEC and worm burden of the AMS-fed group were respectively $27 \%$ and $13 \%$ lower than in the control group. Trial 2 was similar to Trial 1 except that AMS was offered for 30 days to growing Black Head Persian sheep at 170 g/animal/day. The sheep receiving AMS showed a slight reduction in FEC (on average 19\% lower than the control group) but had no effect on worm burden. The current results substantiated previous reports of a suppressing effect of CT on gastrointestinal nematodes of small ruminants. Although the observed anthelmintic activity of AMS was less than expected, such reductions can have practical epidemiological implications in reducing pasture larval contamination. Further studies are needed under field conditions to evaluate the feasibility of using locally available tanniniferous browse as an alternative to synthetic anthelmintics in reducing worm infestations in small ruminants.
\end{abstract}

Keywords: Condensed tannins, tanniniferous browse, faecal egg counts, nematodes, small ruminants

\#Corresponding author. E-mail: romso@yahoo.com

\section{Introduction}

The emergence and spread of gastrointestinal (GI) nematode populations that are resistant to anthelmintic treatments (Prichard, 1994) have contributed significantly to poor productivity in small ruminants particularly those reared in tropical and subtropical environments (Van Wyk et al., 1997; Waller, 1999). Even in regions in developing countries where these chemicals are still effective, most resource-poor farmers find the purchasing of anthelmintics too expensive (Hammond et al., 1997). Development of alternatives for helminth control which are less reliant on chemotherapeutics, is considered the way forward (Gill \& Le Jambre, 1996; Waller, 1999). Although alternatives such as grazing management, selective breeding for resistant hosts, worm vaccines and the use of biological agents have been proposed, their adoption and success under conditions that exist in most developing countries has not been satisfactory. Factors such as finance, technical know-how as well as sustainability play a major role. The use of plants with anthelmintic properties which can reduce or control parasitic nematode infestations is one of the alternative sustainable approaches. Bark of the tropical leguminous tree, Albizia anthelmintica, has been tested and found to have anthelmintic properties against various nematodes (Minja, 2002; Githiori et al., 2003). However, the limited geographical distribution of this species restricts its wider use.

Tannins are polyphenolic compounds widely distributed in the plant kingdom. Field studies have established that nematode-infested sheep fed tannin-rich fodder performed better than those receiving tanninfree fodder (Niezen et al., 1993). Some on-station trials showed significant decreases in FEC and worm burdens when a commercially available quebracho tannin preparation was included in the diets of sheep infested with Trichostrongylus colubriformis (Athanasiadou et al., 2000; Butter et al., 2000) and Haemonchus contortus (Max et al., 2005b). In vitro studies with commercial tannin preparations have also 
demonstrated significant anthelmintic activity against mouse and goat nematodes (Max et al., 2005a). Further work is needed to establish the potential of tannin-rich browse in reducing GI nematode infestation and improving the productivity of small ruminants in tropical regions.

The aim of the current work was to identify tanniniferous browse plants available in the Morogoro region of Tanzania to determine the condensed tannin (CT) concentration and seasonal variation in their leaves, and to test the anthelmintic effects when feeding the leaves of the most promising species to goats and sheep infested with nematodes.

\section{Materials and Methods}

The studies were carried out at the Sokoine University of Agriculture in the town of Morogoro, Tanzania, which is located at $6^{\circ} 48^{\prime} \mathrm{S}-37^{\circ} 36^{\prime} \mathrm{E}$ and $\mathrm{ca}$. $500 \mathrm{~m}$ above see level. The area experiences two rainy seasons with ambient temperatures ranging from 15 to $35{ }^{\circ} \mathrm{C}$. Browse trees and shrubs are widely distributed in most parts of the Morogoro region and constitute a considerable proportion of livestock diets especially during the long dry season because they are drought tolerant and readily available (Mbuya et al., 1994).

Twelve abundant species of browse trees and shrubs from the study area were selected and identified (Table 1). Leafy twigs 10 to $15 \mathrm{~cm}$ from the branch tip were sampled monthly, oven-dried at $55^{\circ} \mathrm{C}$ to a constant weight before being ground to pass through an $1 \mathrm{~mm}$ screen. These samples were screened for CT. The data were used to select five readily available species with high CT concentrations in the study area. Condensed tannin concentrations in the plant samples were determined using the acid-butanol method (HCl-butanol-iron) as described by Porter et al. (1986). Condensed tannin from the commercially available quebracho extract (ATO; Hodgesons Chemicals Ltd., UK) was isolated as described by Giner-Chaves et al. (1997) and used as a reference standard. The CT concentrations were therefore expressed as $\mathrm{g} / \mathrm{kg}$ dry matter (DM) on a quebracho tannin equivalent basis.

Table 1 Description of species of browse trees used

\begin{tabular}{lll}
\hline Species & Family name & Common (Swahili) name \\
\hline Acacia mearnsii & Mimosoideae & Black wattle (Muwati) \\
Acacia polyacantha & Mimosoideae & Falcon’s claw acacia (Mgunga) \\
Acacia tortilis & Mimosoideae & Umbrella thorn (Mgunga) \\
Albizia lebbek & Mimosoideae & East Indian walnut (Mkingu) \\
Azadirachta indica & Meliaceae & Neem tree (Mwarobaini) \\
Gliricidia sepium & Papilionoideae & Mexican lilac (Grisidia) \\
Moringa oleifera & Moringaceae & Horse-radish tree (Mlonge) \\
Persea americana & Lauraceae & Avocado tree (Mparachichi) \\
Morus alba & Moraceae & White mulbery (Mforosadi) \\
Psidium guajava & Myrtaceae & Guava (Mpera) \\
Tamarindus indica & Caesalpinioideae & Tamarind (Mkwaju) \\
\hline
\end{tabular}

Leaves of Acacia polyacantha, collected after the rainy season in June-July, contained the highest levels of CT, and were also the most abundant species in the study area. Enough leaves were therefore collected around June for subsequent animal supplementation studies. Leafy twigs were sampled as before and sun-dried within 24 hours. The leaves, called acacia meal supplement (AMS), were placed in polyethylene bags and kept in a cool, dry room pending the animal studies. Like many other leguminous browse trees, Acacia species contains substantial amounts of crude protein (CP). To balance for differences in nutritive value between the browse-fed and control groups, Pannicum trichocladum (donkey grass) leaves were used because it contains no CT and has CP values comparable to that of $A$. polyacantha. It is palatable 
and was readily available during the trial. Near or early bloom grasses were collected and the succulent leaves were separated from the fibrous main stems and processed to ensure a good quality feed. The leaves were sun-dried and then ground to pass through a 2-mm screen before being stored. The product was used as the grass meal supplement (GMS).

Growing Small East African (SEA) goats and Black Head Persian (BHP) sheep were used in two separate supplementation trials. Goats were purchased from small-scale farmers in the vicinity of the study area. However, sheep were less readily available in the study area and were therefore sourced from a ranch in West Kilimanjaro, Northern Tanzania. The animals were housed in individual wooden pens with raised floors. Goats were offered ad libitum rice straw treated with 5\% urea and sprayed with molasses, whereas the sheep were fed a basal diet consisting of a mixture of chopped Chloris gayana and Brachiaria brizantha hay. The diets of all animals were supplemented daily with 120 - $150 \mathrm{~g}$ of a maize bran-based concentrate (75\% maize bran, $24 \%$ cotton seed cake and 1\% minerals). Once in the experimental house, the animals received a single oral dose of a broad-spectrum anthelmintic (Valbazen ${ }^{\circledR}$ [Albendazole], Novartis East Africa Ltd, Kenya) to clear any worm infestations, and were sprayed with acaricide (Triatix ${ }^{\circledR}$ [Amitraz 12.5\%], Coopers Ltd, Kenya) to control ectoparasites. Due to endemic coccidiosis in the study area a coccidiostat (Trisulmix ${ }^{\circledR}$ [sulfamethasone-trimethoprime] Coophavet, France), was given regularly as a prophylaxis.

Faeces from a naturally infested goat were cultured by the standard Baermann technique (Urquhart et al., 1987) to produce infective stage larvae (L3). The L3 were identified to genus level using keys of Hansen \& Perry (1994). Four nematode genera were identified; Haemonchus (76\%), Oesophagostomum (16\%), Trichostrongylus (6\%) and Cooperia (2\%). The harvested L3 were suspended in distilled water and kept in culture tubes at $4{ }^{\circ} \mathrm{C}$ until they were used to establish experimental infestations in the experimental goats and sheep.

In the goat trial 24 intact SEA bucks aged 12 and 14 months with an average body weight of 15.8 $\pm 2.4 \mathrm{~kg}$ were used. The animals were allowed to acclimatise to the experimental environment and diet for two weeks. On day 1, all goats received a single oral dose of the mixed nematode larvae at a rate of 2000 larvae per $20 \mathrm{~kg}$ body weight. Faecal egg counts were assessed using the McMaster method (Urquhart et al., 1987 ) and were monitored regularly throughout the trial. On day 38 post-infestation the goats were blocked on the basis of their faecal egg counts and randomly allocated into two groups $(\mathrm{n}=12)$. Animals in the AMS group received their daily concentrate allowance in which $100 \mathrm{~g}$ of dry A. polyacantha leaves (CT $=324$ $\pm 95 \mathrm{~g} / \mathrm{kg} \mathrm{DM} ; \mathrm{CP}=169 \mathrm{~g} / \mathrm{kg}$ ) were added. Animals in the control group (GMS) were supplemented with $100 \mathrm{~g} /$ day of the dry ground grass leaves of $P$. trichocladum $(\mathrm{CT}=0.87 \pm 0.02 \mathrm{~g} / \mathrm{kg} \mathrm{DM}$; CP $=174 \mathrm{~g} / \mathrm{kg}$ ). The browse and control supplements were increased to $130 \mathrm{~g}$ /day by day $44 \mathrm{p}$.i. as the goats became more used to consuming the leaves. Any feed refusals were collected and weighed early in the morning before the daily feed allowance was offered. Faeces were visually examined for colour and consistency and faecal DM content was regularly monitored using the standard dry-to-constant-weight method. On day 59 p.i. (i.e. after 21 days on the supplements) all animals were slaughtered humanely and their abomasums and small and large intestines were removed and the worm burdens assessed, as described by Dawson et al. (1999).

Twenty-eight rams, 12 to 14 months of age (18.7 $\pm 2.1 \mathrm{~kg}$ bodyweight), were used in the sheep trial. Its experimental design was similar to that of the goat trial with two major exceptions; AMS was offered ad libitum (150 - $170 \mathrm{~g} /$ day) and the supplementation period was extended to 30 days (i.e. from day 30 to day 60 inclusive).

The data were analysed using a statistical package (GenStat., 2002). The FEC were square root transformed to normalise the data and then analysed as complete randomised designs using one-way analysis of variance (ANOVA) with individual animals as blocks. The impact of treatment on faecal egg output was measured using faecal egg counts taken a day after the onset of treatment to the day of slaughter. Worm burden data were subjected to one-way ANOVA with individual animals as block structures.

\section{Results}

Results for the CT concentrations in leaves of 13 species of browse plants are shown in Table 2. Five species selected for their high CT content were analysed monthly and results are presented in Figure 1. Of the five species, A. polyacantha had the highest overall mean CT concentration ( $283 \mathrm{~g} / \mathrm{kg} \mathrm{DM})$, while the lowest mean value of $58 \mathrm{~g} / \mathrm{kg}$ DM was measured in the Neem tree (Azadirachta indica) samples. 
Table 2 Concentration of extractable condensed tannins (g CT; QT equivalent/kg dry matter [DM]) in the leaves of different browse species (preliminary study; NA = not analysed)

\begin{tabular}{lll}
\hline \multirow{2}{*}{ Species } & \multicolumn{2}{c}{ CT (g/kg DM) } \\
\cline { 2 - 3 } & Dry season & Wet season \\
\hline Acacia mearnsii & 122.6 & NA \\
Acacia polyacantha* & NA & 229.0 \\
Acacia tortilis & NA & 307.4 \\
Albizia lebbek & 8.3 & NA \\
Azadirachta indica* & 50.3 & 48.5 \\
Gliricidia sepium & 7.5 & NA \\
Moringa oleifera & NA & 17.9 \\
Persea americana* & 93.9 & 50.1 \\
Psidium guajava* & 136.6 & 70.1 \\
Tamarindus indica* & NA & 429.7 \\
Morus alba & 5.7 & NA \\
\hline * Species selected & &
\end{tabular}

Seasonal variation in the concentration of CT in leaves of the five selected browse species is shown in Figure 1. Variations in CT levels in the plants followed a characteristic pattern that was similar for all species. The lowest concentration of CT was recorded for samples collected in November to February. The values increased gradually to a peak in July before declining gradually towards November.

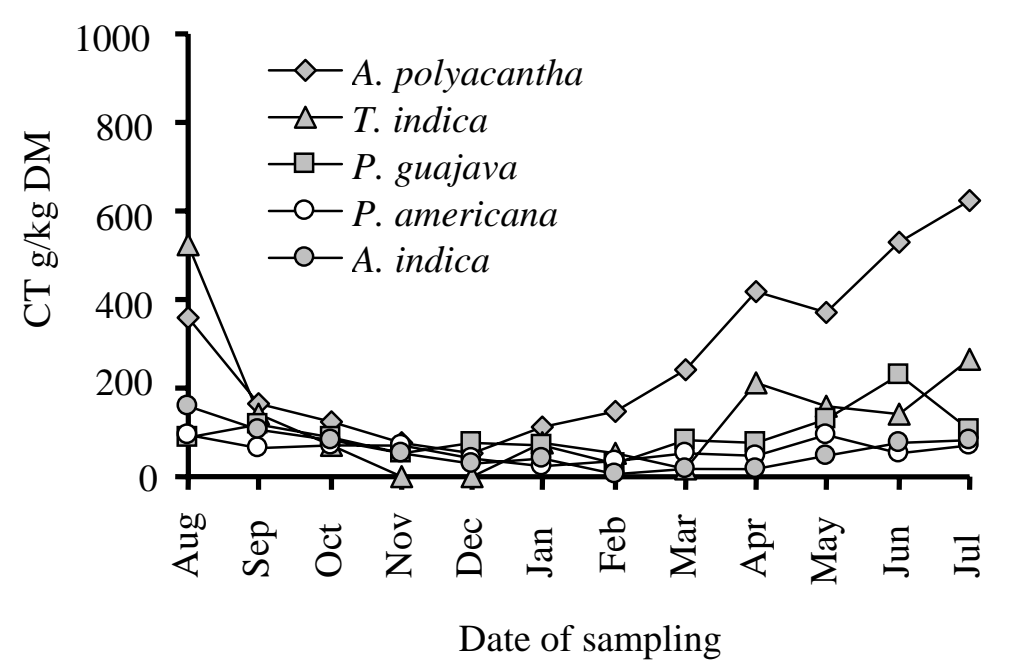

Figure 1 Seasonal changes in the concentration of condensed tannins (CT) in five selected browse plants

Supplementing the diet of the goats with AMS for three weeks did not reduce their FEC ( $>$ > 0.05). However, from day 46 to the day of slaughter the supplemented group tended to have an average of $27 \%$ fewer eggs than the control group (Figure 2). A comparison of egg counts between the two groups on the day of slaughter (day 59 p.i.) showed a reduction of 33\% in the AMS group. The worm burden data (Figure 3) also revealed no reductions $(\mathrm{P}>0.05)$ following the supplementation with AMS. There was a slight 
reduction of $13 \%$ in the worm burden of the large intestine dweller, O. columbianum (means: GMS vs. AMS, 273 vs. 238 worms, respectively).

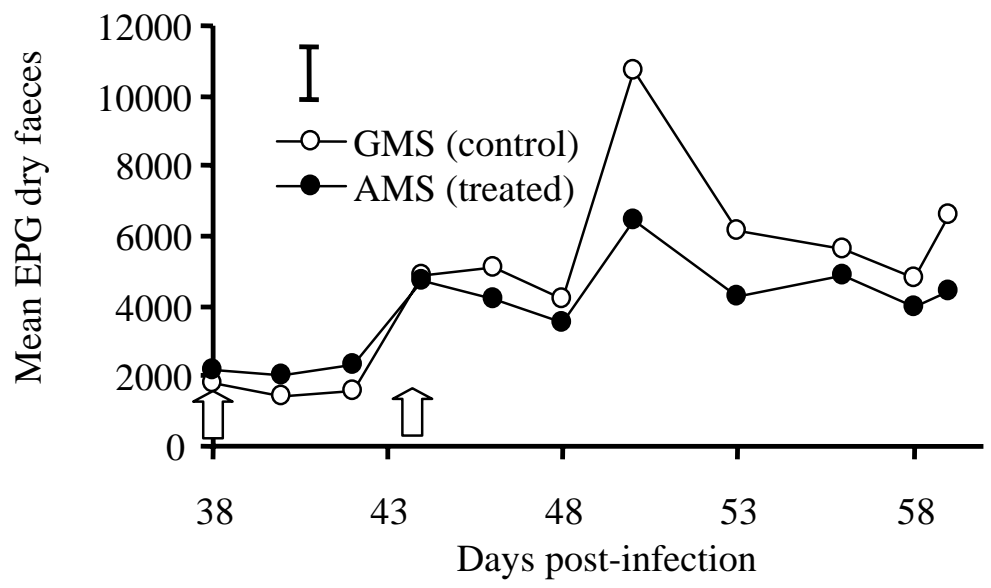

Figure 2 Effect of acacia leaf meal supplement (AMS) on faecal egg counts of goats with mixed nematode infection. The $1^{\text {st }}$ and $2^{\text {nd }}$ arrows indicate onset of supplementation and increment point of AMS, respectively. EPG = eggs per gram

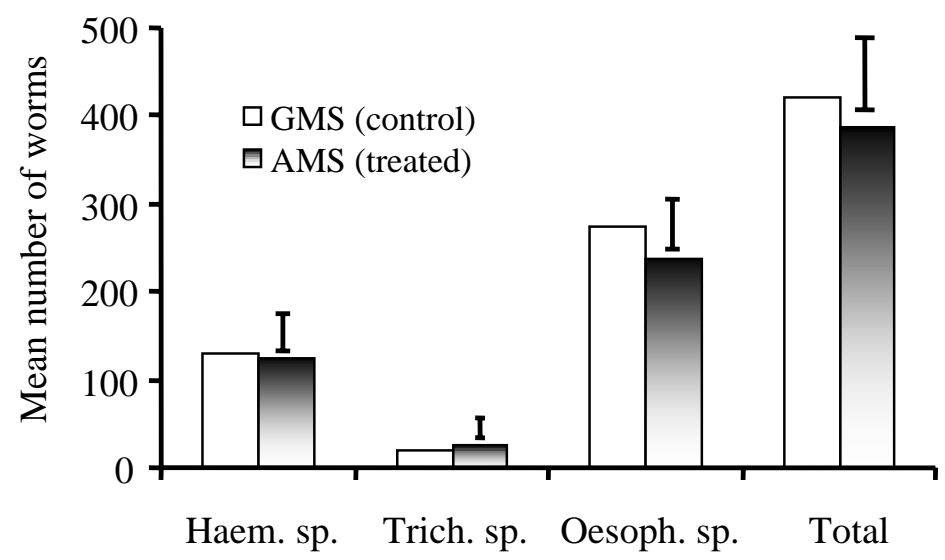

Figure 3 Effect of acacia leaf meal supplement (AMS) on worm burdens of goats with mixed nematode infection. Haem $=$ Haemonchus contortus, Trich $=$ Trichostrongylus colubriformis, Oesoph $=$ Oesophagostomum columbianum

Supplementing the BHP sheep with AMS for 30 days did not reduce their FEC (P > 0.05). However, as the egg count profiles indicate in Figure 4, sheep receiving the supplement excreted fewer eggs than the control. This was equivalent to an average reduction of $19 \%$ between days 31 and 60 p.i. Unlike the goats, this slight reduction was not reflected in the worm burden results (Figure 5), which indicated a slight increase in worm burdens of the AMS group. 


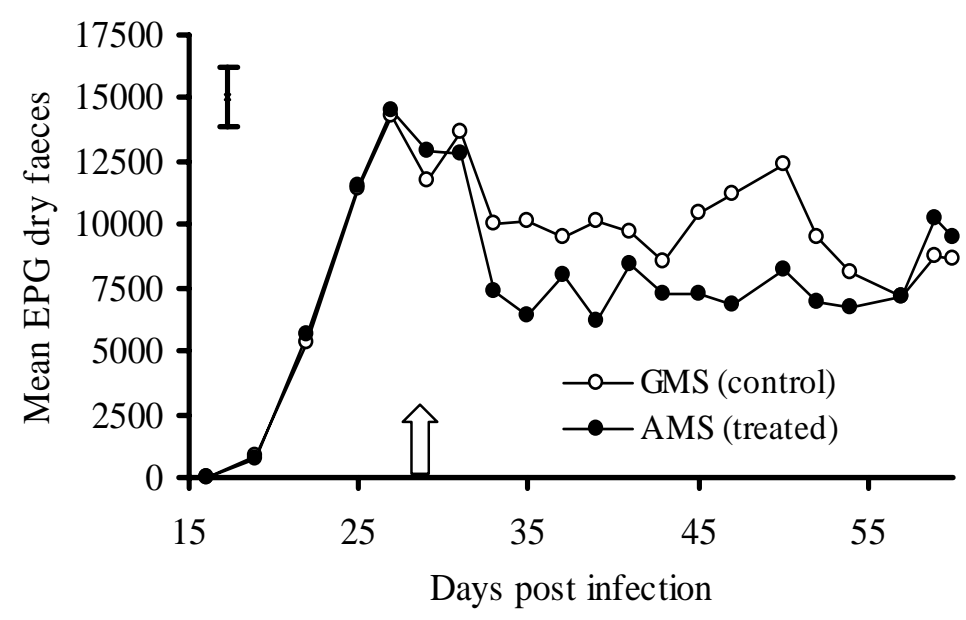

Figure 4 Effect of acacia meal supplement on faecal egg count of sheep with mixed nematode infestation. The arrow in the figure shows the onset of treatment on day 30. EPG = eggs per gram

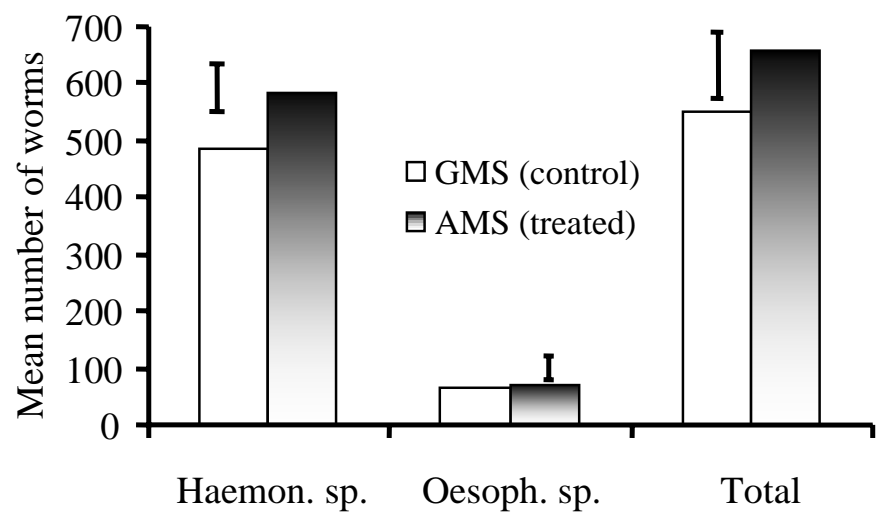

Figure 5 Effect of acacia meal supplement (AMS) on worm burdens of sheep with mixed nematode infestation. Haem = Haemonchus contortus, Oesoph = Oesophagostomum columbianum

Goats in the GMS group produced softer faeces than those in the AMS treatment. This finding was reflected in their mean faecal DM content that was 362 and $388 \mathrm{~g} \mathrm{DM} / \mathrm{kg}$ fresh faeces for GMS and AMS, respectively. The significant treatment $\mathrm{x}$ time interaction $(\mathrm{P}<0.05)$ for faecal $\mathrm{DM}$ content was an indication of increasing faecal water content with time in the GMS group compared to the AMS group (Figure 6). There was no significant difference in faecal DM content between GMS and AMS groups during the sheep trial.

\section{Discussion}

Analysis of CT in leaf samples of different browse trees indicated significant differences in concentrations between species, with the leaves of the leguminous trees being the highest. Acacia polyacantha had the highest CT concentration, and this species is abundant in the study area. It was therefore chosen to be used in the supplementation trials. The current data agreed well with the fact that legumes are a good source of tannins (Jansman, 1993). The average levels of extractable CT reported here were comparable to those usually found in many tropical trees (Lowry et al., 1996; Sotohy et al., 1997; Getachew et al., 2000). The observed pattern of seasonal variation in levels of CT (Figure 1) was probably due to the influence of leaf maturation, i.e. levels of CT reaching a peak as the leaves mature and then starting to decline thereafter. 


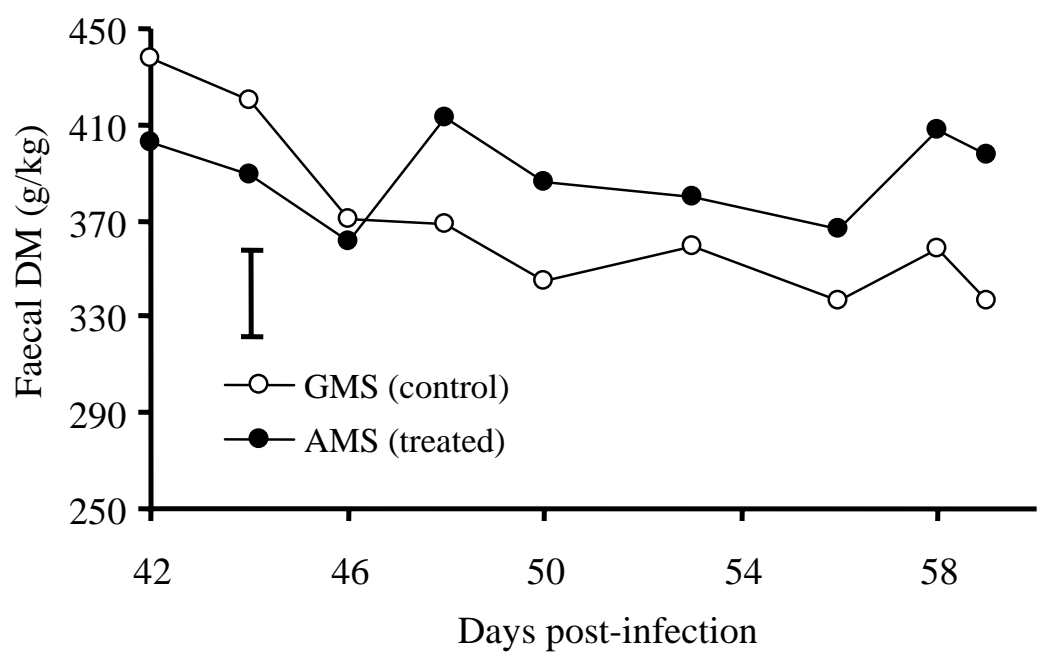

Figure 6 Effect of acacia meal supplement (AMS) on faecal dry mater (DM) content of goats during experimental mixed nematode infection

Most of the plants had their youngest leaves between October and February, explaining why the CT concentrations during this period were at their lowest. A similar trade-off between leaf growth and accumulation of phenolics has been reported by Riipi et al. (2002) who observed a rapid decline in the soluble CT concentration of leaves after an initial increase in young leaves during spring. Environmental or climatic stress, e.g. diseases, predators and drought is an important factor contributing to temporal and seasonal changes in levels of polyphenolics in plants. Levels are known to increase under these conditions (Robbins et al., 1987; Aerts et al., 1999).

In this study goats and sheep experimentally infested with nematodes were supplemented daily with A. polyacantha leaf meal for 20 to 30 days. Supplementation had a slight effect on FEC and worm burdens. These effects were lower than that reported in similar studies in which parasite infested sheep or goats were offered tanniniferous fodder (Kabasa et al., 2000; Paolini et al., 2003a; Min et al., 2004). However, it should be noted that contrasting results from studies on the effect of tannins on nematodes of small ruminants are not uncommon. The administration of quebracho tannins as a drench to sheep has for instance caused a significant reduction in their worm burden of $H$. contortus (Max et al., 2005b). In a similar study using a different batch of QT, no significant effect was observed against the same worm species (Athanasiadou et al., 2001). Furthermore, Minho et al. (2005) demonstrated that feeds containing the same concentration of tannins though from different plant species possess different anthelmintic activities. Tannins are a group of highly heterogeneous phenolic compounds (Jansman, 1993), and therefore differences in their structure could explain their varying biological effects. Tannins from various sources react differently depending on their molecular characteristics (Field \& Lettinga, 1992; Mueller-Harvey \& McAllan, 1992; McNabb et al., 1998) and they are also likely to give different responses against GI nematodes. Recently there has been an increase in the number of studies investigating the effect of dietary tannins on parasitic nematodes particularly in small ruminants. A general observation from these studies is that the effect of tannins on parasitism needs to be measured not only by using FEC and worm burden reduction criteria but also other parameters such as female worm fecundity, egg hatchability, larval development/survival as well as periparturient rise in egg counts. A study by Min et al. (2004) showed for instance that consumption of tanninrich forage (Sericea lespedeza) helped to reduce not only FEC in sheep but also larval development in the pasture. Paolini et al. (2003a; b) demonstrated in goats that the administration of extracts from tanniniferous plants were able to decrease egg excretion due to a decrease in the fecundity of female worms without changes in worm burdens. In another study by Ramirez-Restrepo et al. (2004) ewes grazing tannin-rich Lotus corniculatus had a reduced peri-parturient rise in FEC compared to a group of ewes grazing on tannin-free pastures. Although there was an average FEC reduction of 19\% in the treated (AMS) group in the current 
sheep trial, the total worm burden in the same group was found to be $19 \%$ higher than in the control (GMS) group. This is contrary to our logical expectations but such an observation strongly suggested that the acacia supplement had a negative effect on worm fecundity. If any reductions in faecal egg output are accompanied by reduced egg hatchability and/or larval development/survival, then this effect would be of epidemiological value as far as pasture contamination by infective larva is concerned. Excretion of diarrheic faeces is one of the major clinical signs that characterize nematode infestations. In the present study goats in the GMS treatment had a higher tendency to void diarrheic faeces compared to their counterparts in the AMS group, although worm burdens were similar. This could be an indication that supplementation with acacia leaves could improve the host's resilience to nematode infections. Similar observations were recorded by RamirezRestrepo et al. (2004) who found that ewes grazing L. corniculatus had a consistently lower dag (matting of wool around the hind quarters due to diarrheic faeces) score than those grazing tannin-free pastures.

Despite some positive findings from different studies investigating the effect of tannins and tanniniferous fodder in a nematode parasitized host it is still equivocal on how these effects are brought about. While some studies have shown that the effects of tannins are due to their ability to interact and protect degradation of ruminal proteins (Niezen et al., 1993; Wang et al., 1996), others have demonstrated direct toxic effects of tannins on nematodes (Athanasiadou et al., 2000; Butter et al., 2000; Max et al., 2005a). Findings from similar studies can therefore vary widely depending on the predominant mode of action. It has also been suggested that chemical structure of CT could be more important than their actual concentration as far as biological responses are concerned (McNabb et al., 1998). Results from feeding trials can be influenced and confounded by the presence, in the plants, of other unknown bioactive substances together with differences in nutritional values when different tanniniferous plants are compared. To confidently associate the observed effects to tannins per se, studies need to be designed in such a way that all animals are offered the same tanniniferous plant but one group must be given a CT deactivator such as polyethylene glycol (PEG) in addition.

This study has demonstrated that tanniniferous browse plants are available in the study area and that leaves harvested after the main rainy season have the highest concentration of CT. These can be harvested, dried and stored for use during the rainy season when the incidence of nematode infestation is the highest. Although AMS showed a limited anthelmintic effect its consumption was associated with increased resilience to worm infestations particularly in goats. The best way to harness the limited anthelmintic activity of AMS and possibly other tanniniferous plants is to combine their use with other husbandry techniques designed to reduce the impact of intestinal parasites, such as controlled grazing, improved nutrition, selective chemical anthelmintic treatment as well as selective breeding for resistant hosts. Further studies are needed to assess the effect of feeding tanniniferous browse on various parameters of worm epidemiology such as egg hatchability, larval survival and pasture contamination.

\section{Acknowledgements}

The United Kingdom Department of International Development (DFID) funded this work for the benefit of developing countries. The authors are grateful to technicians and animal attendants at the Departments of Animal Science \& Production and Veterinary Parasitology, Sokoine University of Agriculture, Morogoro, for their assistance.

\section{References}

Aerts, R.J., Barry, T.N. \& McNabb, W.C., 1999. Polyphenols and agriculture: Beneficial effects of proanthocyanidins in forages. Agric. Ecos. Environ. 75, 1-12.

Athanasiadou, S., Kyriazakis, I., Jackson, F. \& Coop, R.L., 2000. Consequences of long-term feeding with condensed tannins on sheep parasitised with Trichostrongylus colubriformis. Int. J. Parasit. 30, 1025-1033.

Athanasiadou, S. Kyriazakis, I., Jackson, F. \& Coop, R.L., 2001. Direct anthelmintic effects of condensed tannins towards different gastrointestinal nematodes of sheep: in vitro and in vivo studies. Vet. Parasitol. 99, 205 - 219.

Butter, N.L., Dawson, J.M., Wakelin, D. \& Buttery, P.J., 2000. Effect of dietary tannin and protein concentration on nematode infection (Trichostrongylus colubriformis) in lambs. J. Agric. Sci., Camb. 137, 461-469. 
Dawson, J.M., Buttery, P.J., Jenkins, D., Wood, C.D. \& Gill, M., 1999. Effect of dietary quebracho tannin on nutrient utilisation and tissue metabolism in sheep and rats. J. Sci. Food Agric. 79, 1423-1430.

Field, J.A. \& Lettinga, G., 1992. Toxicity of tannic compounds to micro-organisms. In: Plant Polyphenols. Eds. Hemingway, R.W. \& Laks, P.E., Plenum Press, NY, USA. pp. 673-692.

GenStat., 2002. GenStat Release 6.1 user's guide. Lawes Agricultural Trust, Rothamsted Experimental Station, UK.

Getachew, G., Makkar, H.P.S. \& Becker, K., 2000. Tannins in tropical browses: Effects on in vitro microbial fermentation and microbial protein synthesis in media containing different amounts of nitrogen. J. Agric. Food Chem. 48, 3581-3588.

Gill, H.S. \& Le Jambre, L.F., 1996. Preface - Novel approaches to the control of helminth parasites of livestock. Int. J. Parasitol. 26, 797-798.

Giner-Chavez, B.I., Van Soest, P.J., Robertson, J.B., Lascano, C., Reed, J.D. \& Pell, A.N., 1997. A method for isolating condensed tannins from crude plant extracts with trivalent ytterbium. J. Sci. Food Agric. 74, 359-368.

Githiori, J.B., Höglund, J., Waller, P.J. \& Baker, R.L., 2003. The anthelmintic efficacy of the plant, Albizia anthelmintica, against the nematode parasites Haemonchus contortus of sheep and Heligmosomoides polygyrus of mice. Vet. Parasitol. 116, 23-34.

Hammond, J.A., Fielding, D. \& Bishop, S.C., 1997. Prospects for plant anthelmintics in tropical veterinary medicine. Vet. Res. Comm. 21, 213-228.

Hansen, J. \& Perry, B., 1994. The epidemiology, diagnosis and control of helminth parasites of ruminants. ILCA, Addis Ababa, Ethiopia.

Jansman, A.J.M., 1993. Tannins in feedstuff for simple-stomached animals. Nutr. Res. Rev. 6, 209-239.

Kabasa, J.D., Opuda-Abiso, J. \& Ter Meulen, U., 2000. The effect of oral administration of polyethylene glycol on FEC in pregnant goats grazed on browse containing condensed tannins. Trop. Anim. Health Prod. 32, 73-86.

Lowry, J.B., McSweeney, C.S. \& Palmer, B., 1996. Changing perceptions of the effect of plant phenolics on nutrient supply in the ruminant. Aust. J. Agric. Res. 47, 829-842.

Max, R.A., Wakelin, D., Craigon, J., Kassuku, A.A., Kimambo, A.E. \& Mtenga, L.A., 2005a. Effect of two commercial preparations of condensed tannins on the survival of gastrointestinal nematodes of mice and goats in vitro. S. Afr. J. Anim. Sci. 35, 213-220.

Max, R.A., Wakelin, D., Dawson, J., Kimambo, A.E., Kassuku, A.A., Mtenga, L.A. \& Buttery, P.J. 2005b. Effect of quebracho tannin on faecal egg counts, worm burdens and performance of temperate sheep with experimental nematode infections. J. Agric. Sci., Camb. 143, 519-527.

Mbuya, L.P., Msanga, H.P., Ruffo, C.K., Birnie, A. \& Tengnäs, B., 1994. Useful Trees and Shrubs for Tanzania. Technical Handbook No. 6. SIDA’s Regional Soil Conservation Unit, (RSCU).

McNabb, W.C., Peters, J.S., Waghorn, G.C., Foo, L.Y. \& Jackson, F.S., 1998 Effect of CT prepared from several forage on the in vitro precipitation of Rubisco protein and its digestion by trypsin and chymotrypsin. J. Sci. Food Agric. 77, 201-212.

Min, B.R., Pomroy, W.E., Hart, S.P. \& Sahlu, T., 2004. The effect of short-term consumption of a forage containing condensed tannins on gastro-intestinal nematode parasite infections in grazing wether goats. Small Rumin. Res. 51, 279-283.

Minho, A.P., Gennari, S.M. \& Abdalla, A.L., 2005. The effect of condensed tannins on Haemonchus contortus in sheep experimentally infected. Proc. Br. Soc. Anim. Sci. pp. 139.

Minja, M.M.J., 2002. Validation of Albizia anthelmintica as an anthelmintic against helminths in calves. Proceedings of the second DFID Livestock Production Programme Link Project (R 7798). Workshop for Smallstock Holders, Sokoine University of Agriculture, Morogoro, Tanzania. pp. 31-35.

Mueller-Harvey, I. \& McAllan, A.B., 1992. Tannins - their biochemistry and nutritional properties. In: Advances in Plant Cell Biochemistry and Biotechnology, Vol. 1. Ed. Morrison, I.M., London, JAI Press. pp. 149-214.

Niezen, J.H., Waghorn, T.S., Waghorn, G.C. \& Charleston, W.A.G., 1993. Internal parasites and lamb production - a role for plants containing condensed tannins? Proc. New Zealand Soc. Anim. Prod. 53, 235-238. 
Paolini, V., Frayssines, A., De La Farge, F., Dorchies, P. \& Hoste, H., 2003a. Effects of condensed tannins on established populations and on incoming larvae of Trichostrongylus colubriformis and Teladorsagia circumcincta in goats. Vet. Res. 34, 331-339.

Paolini, V., Bergeaud, J.P., Grisez, C., Prevot, F., Dorchies, P. \& Hoste, H., 2003b. Effects of condensed tannins on goats experimentally infected with Haemonchus contortus. Vet. Parasitol. 13, 253-261.

Porter, L.J., Hrstich, L.N. \& Chan, B.G., 1986. The conversion of procyanidins and prodelphinidins to cyanidin and delphinidin. Phytochem. 25, 1214-1218.

Prichard, R.K., 1994. Anthelmintic resistance. Vet. Parasitol. 54, 259-268.

Ramirez-Restrepo, C.A., Barry, T.N., Lopez-Villalobos, N., Kemp, P.D. \& McNabb, W.C., 2004. Use of L. corniculatus containing CT to increase lamb and wool production under commercial dryland farming conditions without the use of anthelmintics. Anim. Feed Sci. Technol. 117, 85-105.

Riipi, M., Ossipov, V., Lempa, K., Haukioja, E., Koricheva, J., Ossipova, S. \& Pihlaja, K., 2002. Seasonal changes in birch leaf chemistry: Are there trade-offs between leaf growth and accumulation of phenolics? Oecologia 130, 380-390.

Robbins, C.T., Hanley, T.A., Hagerman, A.E., Hjeljord, O., Baker, D.L., Shwarz, C.C. \& Mautz, W.W., 1987. Role of tannins in defending plants against ruminants: reduction in protein availability. Ecology 68, 98-107.

Sotohy, S.A., Sayed, A.N. \& Ahmed, M.N., 1997. Effect of tannin-rich plant (Acacia nilotica) on some nutritional and bacteriological parameters in goats. Deutsche Tierarztliche Wochenschrift 104, 432-435.

Urquhart, G.M., Armour, J., Duncan, J.L., Dunn, A.M. \& Jennings, F.W., 1987. Veterinary Parasitology. Longman Scientific \& Technical, Bath Press, Avon, United Kingdom.

Van Wyk, J.A., Malan, F.S. \& Bath, G.F., 1997. Rampant anthelmintic resistance in sheep in South Africa What are the Options? In: Managing Anthelmintic Resistance in Endoparasites. Eds. Van Wyk, J.A. \& Van Schalkwyk, P.C., Workshop held at the 16th Int. Conference of the WAAVP, Sun City, South Africa. pp. 51-63.

Waller, P.J., 1999. International approaches to the control of nematode parasites of livestock. Int. J. Parasit. 29, 155-164.

Wang, Y., Douglas, G.C., Barry, T.N. \& Foote, A.G., 1996. Effect of CTs in Lotus corniculatus upon the digestion of methionine and cysteine in the small intestine of sheep. J. Agric. Sci., Camb. 127, 413-421. 